\title{
Role of Vitamin-D Supplementation In Prevention of Preeclampsia
}

\author{
Dr.Anupama.H , Dr.Sunanda .K ,Dr Jyothirmayee.R \\ Department Of Obstetrics \& Gynaecology, Gandhi Medical College,Secunderabad,Telangana State, \\ India
}

\begin{abstract}
Objectives:- To assess whether Vitamin-D supplements given to women during pregnancy can safely improve maternal and neonatal outcome by preventing Preeclampsia.

Materials And Methods: This is an interventional and prospective study by including primi and multi gravida attending antenatal clinic-Dept. of $O B G$, Gandhi hospital, Secunderabad. Cases-50 pregnant women supplemented with Vit-D during antenatal period.Age and gravida matched controls-50 pregnant women not supplemented with Vit-D..For all the woman included in the study, that is, cases and controls vitamin- $d$ level was estimated twice, once in $1^{\text {st }}$ trimester and again in $3^{\text {rd }}$ trimester. Supplementation of Vit-D was done to cases, Dosage- 60000IU sachets once a week for three months that is for entire second trimester. These woman were followed until delivery. Maternal and fetal outcome was noted in terms of mode of delivery, gestational age at delivery, birth weight of baby, Incidence of preeclampsia, eclampsia, GDM etc. Incidence of preeclampsia has been calculated among cases and controls.

Results: Among 100 cases and controls -4 cases and 9 controls developed preeclampsia in our study. Incidence of preeclampsia is $18 \%$ among controls, $8 \%$ among cases, more among controls in our study. $p$ vaiue is $0.234, p$ value $<0.05$ is taken as significant. $p$ value of our study is insignificant may be because of the small sample size. Incidence of mild preeclampsia-cases- $6 \%$,controls-8\%, severe preeclampsia-cases-2\%,controls $10 \%$.Incidence of both mild and severe preeclampsia is more among controls than in cases.

Conclusion: Incidence of preeclampsia in our study is 13\% (13 of 100) 4(incidence8\%) cases and 9(incidence18\%) controls developed preeclampsia. Incidence of mild and severe preeclampsia, abruption, eclampsia, LBW, GDM, operative delivery are more among controls though the $p$ values are not significant which may be due to smaller sample size. Mean Vitamin D levels were lower in preeclamptic woman compared to normal woman with a statistically significant $p$ value $(p<0.05)$.Our study shows a positive association between vitamin $D$ and preeclampsia .To establish a casual association between vitamin d deficiency and preecalmpsia , a randomised control trial of vitamin D supplementation among woman with Vitamin D deficiency is needed.
\end{abstract}

\section{Introduction}

We get Vitamin - D is a fat soluble vitamin, primarily from exposure to sunlight and foods such as fish oil, eggs, fortified diary products. Vitamin - D deficiency is common in India though it is a tropical country. Pre eclampsia is a form of hypertensive disorder unique to pregnancy, etiology has many factors both known and unknown, numerous suggested but not yet confirmed. Theories under consideration are Immunological disorder, genetic disorder and abnormal placentation. Vitamin D deficiency is one of the factors in etiology of Preeclampsia. Vitamin D deficiency is thought to be common among pregnant women. Supplementation during pregnancy has been suggested as an intervention to protect against adverse gestational outcome including Preeclampsia ${ }^{1}$. Maternal vitamin D levels have been shown to positively correlate with birthweight centile ${ }^{2}$. Hypovitaminosis D is associated with impaired glucose tolerance and diabetes in the general population ${ }^{3}$. However, the evidence for an association between low vitamin D levels and gestational diabetes mellitus (GDM) is conflicting. Vitamin D deficiency $(<37.5 \mathrm{nmol} / \mathrm{l})$ has been associated with a fourfold increase risk of primary caesarean section ${ }^{4}$.Vitamin $\mathrm{D}$ deficiency is associated with bacterial vaginosis in pregnant women ${ }^{5}$.Neonatal vitamin $\mathrm{D}$ levels are correlated with those of their mother, with maternal vitamin D deficiency increasing the risk of neonatal vitamin D deficiency ${ }^{6}$. Vitamin D deficiency is a major cause of hypocalcaemic seizures in neonates and infants. Hypovitaminosis D is associated with impaired growth and bone development in the fetus ${ }^{7}$. Evidence is accruing to show that maternal $25(\mathrm{OH}) \mathrm{D}$ insufficiency may lead to suboptimal bone size and density after birth without overt rachitic change ${ }^{7}$. This is likely to lead to an increased risk of osteoporotic fracture in later life. Low maternal vitamin D intake in pregnancy is associated with wheeze and asthma in the offspring. Low cord blood $25(\mathrm{OH}) \mathrm{D}$ concentrations have been associated with respiratory syncytial virus bronchiolitis. Cord blood $25(\mathrm{OH})$ D is correlated with mononuclear cell release of IFN- $\gamma$ and hence Th1 cell development ${ }^{8}$.There is no data to support routine screening for vitamin D deficiency in pregnancy. As the test is expensive, universal supplementation is comparatively cost effective and safe. 
HIGH RISK GROUPS for vitamin D Deficiency - vitamin D deficiency is more common in pigmented women (Melanin absorbs UVB). Deficiency is more common in winter ${ }^{9}$. Pre pregnancy obesity has been associated with low levels of vitamin $\mathrm{D}^{10}$. Other factors associated with Vitamin D deficiency are gastrointestinal conditions limiting fat absorption, immobility, etc.,

Normal serum level of at least $20 \mathrm{ng} / \mathrm{ml}(50 \mathrm{nmol} / \mathrm{l})$ is needed to avoid bone problems. When $25(\mathrm{OH})$ D level $<20 \mathrm{ng} / \mathrm{ml}(50 \mathrm{nmol} / \mathrm{l})$ leads to vitamin deficiency

Vitamin D insuffficiency $25(\mathrm{OH}) \mathrm{D}$ level $<32 \mathrm{ng} / \mathrm{ml}(80 \mathrm{nmol} / \mathrm{l})^{11}$.

Recommended dietary allowences

\begin{tabular}{|l|l|l|}
\hline \multirow{2}{*}{ VITAMIN D } & PREGNANCY (Age 15 - 40) & LACTATION (Age 15 - 40) \\
\cline { 2 - 3 } & $15 \mu \mathrm{g}$ & $15 \mu \mathrm{g}(600 \mathrm{IU} / \mathrm{day})$ \\
\hline
\end{tabular}

Recommendation measured as adequate intake by food and nutrition board at the Institute of Medicine $2011^{12}$.

\section{Safety And Toxicity:}

Requirement of vitamin D in women may be upto $6000 \mathrm{IU} /$ day. High risk woman are advised to take atleast $1000 \mathrm{IU} /$ day. Supplemental doses of $4000 \mathrm{IU} /$ day were safe and most effective in pregnant women compared to lower dose ${ }^{13}$. All pregnAnt women should take $400 \mathrm{IU}(10 \mu \mathrm{g})$ of vitamin D per day(NICE 2012). Vitamin D toxicity occurs at an intake of $10-100$ times the RDA. In adults very high doses of vitamin D $(3-5$ lakh IU intramuscular bolus) may be associated with increased risk of fractures and such high doses are not recommended in pregnancy ${ }^{14}$.

Regarding the role of Vitamin D in pathogenesis of pre eclampsia, there are several mechanisms by which vitamin $\mathrm{D}$ could potentially prevent or atleast delay the progression to preeclampsia.One potential mechanism relates to a defective control of effector $\mathrm{T}$ cells by regulatory $\mathrm{T}$ cells. This can lead to poor placental invasion, which in turn leads to release of placental derived vasoconstrictor factors ${ }^{15}$.Vitamin $\mathrm{D}$ receptors on immune cells express key enzymes involved in hormonal activation(CYP2B1)and catabolism (CYP24A1) of vitamin D metabolites,suggesting that the availability and effectiveness of calcitriol can be directly regulated by cells of immune system. The net result of calcitriol on immune system is towards a more tolerogenic state ${ }^{16}$.In vitro studies have demonstrated that calcitriol administration leads to upregulation of regulatory $\mathrm{T}$ cell responses while proinflammatory responses are downregulated .Vitamin D may help to control the hormones affecting blood pressure. The active form of vitamin D has been shown to regulate the transcription and function of genes associated with placental invasion ,normal implantation and angiogenesis ${ }^{17}$. Receptors for $1,25(\mathrm{OH}) \mathrm{D}$ have been found in target tissues that regulate blood pressure.Both hypocalcemia and hypercalcemia affect blood pressure and in both cases, vitamin D metabolism is involved .

It has been observed that decreased calcitriol levels during preeclampsia impair intestinal calcium absorption leading to hypocalcemia. As a compensatory mechanism there is increase in tubular reabsorption of calcium and it leads to hypocalciuria during preeclampsia ${ }^{18}$. It has been reported that hypocalciuria predicts preeclampsia long before clinical manifestation exist.Calcitriol has stimulatory effect on expression of VEGF in vascular smooth muscle cells.Calcitriol may be important in preventing cholesterol uptake by macrophages and vascular smooth muscle proliferation and atheromatous pathology ${ }^{19}$.Vitamin D receptors on heart and blood vessels suggest vitamin D has a cardioprotective effect and has a role in controlling inflammation, effects BP through influence on Reticulo endothelial system ${ }^{20}$. Therefore vitamin D is likely to play an important role in immune and CVS changes necessary for healthy pregnancy.

\section{Materials and Methods}

This is an interventional and prospective study by including primi and multi gravida attending antenatal clinic-Dept. of OBG,Gandhi hospital,Secunderabad.Age and gravid matched pregnant women were taken as cases and controls according to inclusion and exclusion criteria after proper counseling.For cases vitamin $\mathrm{D}$ was supplemented and controls received only regular antenatal care.For all the women included in the study that is cases and controls vitamin- D level was estimated twice once in $1^{\text {st }}$ trimester and again in $3^{\text {rd }}$ trimester after taking consent of the patients. Period of study-January 2014 to August2015. This study has been approved by ethical committee of the Institution. Serum $25(\mathrm{OH}) \mathrm{D}$ level was measured by High performance liquid chromatography method .

\section{Inclusion Criteria}

1. Age 20 to 30 years

2. Primi and multi gravida attending antenatal clinic,Dept. of OBG,Gandhi hospital

3. Singleton pregnancy

4. Gestational age $<12$ weeks 


\section{Exclusion Criteria}

1. Chronic hypertension cases

2. Gestational age $>12$ weeks

3. Medical disorders complicating pregnancy like Diabetes,SLEandRheumatoid arthritis.

4. Vitamin D deficient(frank deficiency less than 20ng/ml)as they have to be treated to avoid other complications due to vitamin D deficiency.

5. Previous history of pre eclampsia in a case of multigravida

6. Smokers

Supplementation of Vitamin D was done to ante natal mothers,in form of 60000IU sachets once a week for three months for entire second trimester.These women were followed until delivery .Maternal and fetal outcome was noted-mode of delivery,GA at delivery,birth weight of baby,Incidence of preeclampsia,eclampsia,GDM etc. Incidence of preeclampsia has been calculated among cases and controls. RESULTS

Among 100 cases and controls -4 cases and 9 controls developed preeclampsia in our study.Incidence of preeclampsia was $12.6 \%$ (10 of 79 ) in age group 20-25, 14.2\%(3 of 21) in age group 25-30.Our study included both primi and multi gravid(50 primi and 50 multi).There were 10 cases in primi incidence $20 \%, 3$ cases in multi incidence 6percent.Incidence is more in primi- primiparity is a known risk factor for preeclampsia. Obesity is taken as BMI>30.Prevalence of obesity is more among preeclamptic woman.Mean BMI Among preeclamptic woman is 24.1 , among nonpreeclamptic woman is 21.8. Incidence of preeclampsia is $18 \%$ among controls, $8 \%$ among cases, more among controls in our study. $\mathrm{p}$ vaiue is $0.234, \mathrm{p}$ value $<0.05$ is taken as significant. $p$ value of our study is insignificant may be because of the small sample size. Incidence of mild preeclampsia-cases- $6 \%$,controls- $8 \%$, severe preeclampsia-cases- $2 \%$,controls $10 \%$.Incidence of both mild and severe preeclampsia is more among controls than in cases.

\section{Discussion}

Our study is a prospective interventional case control study by including primi and multi gravida attending antenatal clinic-Dept. of OBG,Gandhi hospital,Secunderabad. Parity matched Cases and controls were chosen according to inclusion and exclusion criteria .Supplementation of Vit-D was done to cases,Dosage60000IU sachets once a week for three months that is for entire second trimester.Serum vitamin D level was measured by HPLC method.During antenatal checkups along with regular obstetric examination BP and UA were measured.Diagnosis of preeclampsia was done according to ACOG 2013 task force criteria.Among 100 cases and controls -4 cases and 9 controls developed preeclampsia in our study

Incidence Of Preeclampsia Among Cases(Vitamin D Supplemented) And Controls(Non Supplemented) In Different Studies-Comparitive Table

\begin{tabular}{|l|l|l|}
\hline STUDY & CASES & CONTROLS \\
\hline ITO ET AL & 10.9 & $16.9 \%$ \\
\hline HCCSCA-CREIZEL ET AL & $2.5 \%$ & $3.06 \%$ \\
\hline HAUGEN ET AL & $5.1 \%$ & $6 \%$ \\
\hline $\begin{array}{l}\text { CASECONTROL STUDY ,PGIMS- } \\
\text { PARULET AL }\end{array}$ & $4 \%$ & $10 \%$ \\
\hline OUR STUDY & $8 \%$ & $18 \%$ \\
\hline
\end{tabular}

In all the above studies incidence is lower in cases-vitamin D supplemented group than in non supplemented or control group.Our results are similar to the above mentioned studies.

Mean Vitamin D Level-First Trimester Among Preeclamptic And Normal Woman In Different StudiesComparitive Table

\begin{tabular}{|l|l|l|}
\hline Study & $\begin{array}{l}\text { Mean vitamin D level in } \\
\text { preclamptic woman }\end{array}$ & $\begin{array}{l}\text { Mean vitamin D level in normal } \\
\text { woman }\end{array}$ \\
\hline CAMILLE ET AL & $27.4 \mathrm{ng} / \mathrm{ml}$ & $28.8 \mathrm{ng} / \mathrm{ml}$ \\
\hline $\begin{array}{l}\text { CASE CONTROL STUDY, } \\
\text { QUEBEC-MADONNA ET AL }\end{array}$ & 18.8 & 20.92 \\
\hline BAKER ET AL COHORT & 30 & 39.2 \\
\hline $\begin{array}{l}\text { PROSPECTIVE } \\
\text { STUDY,CANADA-WEI ET AL }\end{array}$ & 20.4 & 22.4 \\
\hline OUR STUDY & $37.7 \mathrm{ng} / \mathrm{ml} / \mathrm{ml}$ & \\
\hline
\end{tabular}

In all the above mentioned studies mean vitamin $\mathrm{D}$ level is low among preeclamptic woman than in normal womanOur results are similar to the above mentioned studies 
Mean Vitamin D Value -Third Trimester Among Preeclamptic Woman And Normal Woman-Comparitive Table

\begin{tabular}{|l|l|l|}
\hline Study & $\begin{array}{l}\text { Mean vitamin D value in } \\
\text { preeclamptic woman }\end{array}$ & $\begin{array}{l}\text { Mean vitamin D value in } \\
\text { normal woman }\end{array}$ \\
\hline $\begin{array}{l}\text { UK STUDY(2005-8)-LECHTERMANN } \\
\text { ET AL }\end{array}$ & 18.21 & 49.2 \\
\hline $\begin{array}{l}\text { PROSPECTIVECOHORT } \\
\text { STUDY,CANADA-WEI ET AL }\end{array}$ & 19.56 & 22.8 \\
\hline OUR STUDY & $30.4 \mathrm{ng} / \mathrm{ml}$ & $44 \mathrm{ng} / \mathrm{ml}$ \\
\hline
\end{tabular}

In all the above mentioned studies mean vitamin $\mathrm{D}$ level is low among preeclamptic women than in normal women Our results are similar to the above mentioned studies Kaur et al, found that supplementation of vitamin D in 60,000 IU during 6th and 7th month of pregnancy increases protein, DNA and RNA content of placenta and improved the placental growth ${ }^{21}$. Recent studies have also demonstrated the reno-protective effects of Vitamin D analogs. In a controlled trial of 5644 women in the United Kingdom, those receiving a dietary supplement of halibut liver oil containing 900 IU of vitamin D per day starting at $20 \mathrm{wk}$ gestation demonstrated a $32 \%$ decreased odds of preeclampsia compared with women who did not receive the supplement ${ }^{22}$. Dose dependent association between vitamin D level and preeclampsia was established by Hollis and Wagner ${ }^{23}$. Olafsdottir et al-an observational study in Icelandic woman, showed a U shaped relation between vitamin D intake at 11-15 weeks gestation and risk of hypertensive disorders ${ }^{24}$.Various recent studies have demonstrated a negative association between albuminuria and Vitamin D levels ${ }^{25}$.

Our study has demonstrated a positive association between vitamin D level and preeclampsia.Strengths of our study are it is a prospective study-vitamin D levels were measured and supplementation was given before the onset of preeclampsia,vitamin D level measurement is a better biomarker of status than food quesstionaries as used in some studies, vitamin d level is measured twice before and after supplementation -longitudinal status and effect on early and late gestation could be evaluated.Vitamin D value was measured by high performance liquid chromatography method which has acceptable accurancy. Confounding factors were minimized to the possible extent - cases and controls were age and parity matched. Though vitamin D supplementation-role in preeclampsia is not yet established, supplementation has other advantages in pregnancy both to mother and growing fetus without any toxicity and side effects.

Vitamin D supplementation has effect both in early and late stages of pregnancy. Vitamin D is important for fetal and childhood bone development. New research has shown that it plays a wider role in health and disease prevention. In normal pregnancies, circulating maternal concentration of $1,25(\mathrm{OH})_{2} \mathrm{D}$ is elevated from the first trimester onwards ${ }^{26}$. Local production of $1,25(\mathrm{OH})_{2} \mathrm{D}$ may be important for its increased concentration in the early stage of pregnancy, this has been suggested to influence implantation, partly through the immunomodulatory effect and partly by regulation of the target genes associated with implantation. The elevation of $1,25(\mathrm{OH})_{2} \mathrm{D}$ in the early stage of pregnancy could reflect its role in implantation, as demands to meet increased calcium requirements for the fetal skeletal development come later in pregnancy. Vitamin D might also be important for the maintenance of a normal pregnancy through its impact on the maternal immune response to the fetus ${ }^{27}$.

\section{Conclusion}

Incidence of preeclampsia in our study is $13 \%$ (13 of 100) 4(incidence $8 \%$ ) cases and 9(incidence $18 \%$ ) controls developed preeclampsia. In our study incidence is more in primigravida .Incidence of preeclampsia is similar among different age groups,different occupations and different communities included in our study. Majority of cases had onset of preeclampsia after 34 weeks of gestation. Preeclamptic woman had increased rate of obstetric and neonatal complications and increased rate of operative delivery. Mean Vitamin D levels were lower in preeclamptic women compared to normal women with a satistically significant $p$ value $(p<0.05)$. Our study shows a positive association between vitamin D and preeclampsia. To establish a casual association between vitamin $\mathrm{D}$ deficiency and preeclampsia,a randomised multicentric control trial of vitamin $\mathrm{D}$ supplementation among woman with Vitamin D deficiency is needed.

Limitations of our study are it is a case control study-can overestimate the effect size of the association and makes temporal association less clear, selection bias and confounding factors cannot be eliminated totally. Sample size is small -overestimates the prevalence rates, it includes similar population. Vitamin D deficient group is excluded from our study as it is unethical to leave them untreated as controls as vitamin d deficiency has other side effects on pregnancy if not preeclampsia, the present study included only insufficient and sufficient group.Consensus for vitamin D levels(normal, insufficiency,deficiency)are taken according to non pregnant levels as there are no specific guidelines for vitamin D values in pregnant woman. 


\section{References}

[1]. Roberts $\mathbf{J}$.preeclampsia a two stage disorder.In Lyal F,Belfort M,Preeclampsia etiology and clinical practice .Newyork:Cambridge university Press 2007.pp.183-94.

[2]. Robinson CJ, Wagner CL, Hollis BW, Baatz JE, Johnson DD. Maternal vitamin D and fetalgrowth in early-onset severe preeclampsia. Am J Obstet Gynecol 2011;204:556.e1-4

[3]. Maghbooli Z, Hossein-nezhad A, Karimi F, Shafaei AR, Larijani B. Correlation between vitamin D3 deficiency and insulin resistance in pregnancy. Diabetes Metab Res Rev 2008;24:27-32.

[4]. Merewood A, Mehta SD, Chen TC, Bauchner H, Holick MF. Association between vitamin D deficiency and primary cesarean section. J Clin Endocrinol Metab 2009;94:940-5.

[5]. Hensel KJ, Randis TM, Gelber SE, Ratner AJ. Pregnancy-specific association of vitamin D deficiency and bacterial vaginosis. Am J Obstet Gynecol 2011;204:41.e1-9.

[6]. Bowyer L, Catling-Paull C, Diamond T, Homer C, Davis G, Craig ME. Vitamin D, PTH andcalcium levels in pregnant women and their neonates. Clin Endocrinol (Oxf) 2009;70:372-7.

[7]. Morley R, Carlin JB, Pasco JA, Wark JD. Maternal 25-hydroxyvitamin D and parathyroid hormone concentrations and offspring birth size. J Clin Endocrinol Metab 2006;91:906-12.

[8]. Chi A, Wildfire J, McLoughlin R, Wood RA, Bloomberg GR, Kattan M, et al. Umbilical cord plasma 25-hydroxyvitamin D concentration and immune function at birth: the Urban Environment and Child hood Asthma study. Clin Exp Allergy 2011;41:84250.

[9]. Hyppönen E, Power C. Hypovitaminosis D in British adults at age $45 \mathrm{y}$ : nationwide cohort study of dietary and lifestyle predictors. Am J Clin Nutr 2007;85:860-8.

[10]. Bodnar LM, Catov JM, Roberts JM, Simhan HN. Prepregnancy obesity predicts poor vitamin D status in mothers and their neonates. J Nutr 2007;137:2437-4

[11]. Hollis BW, Wagner CL. Normal serum vitamin levels. N Engl J Med 2005;352:515-6.

[12]. Cunningham FG,Leveno KJ,Bloom SL,Sponge CY,Dashe JS,Hoffman BL et al ,Williams Obstetrics 2014;24: 179.

[13]. Hollis BW, Johnson D, Hulsey TC, Ebeling M, Wagner CL. Vitamin D supplementation during pregnancy: double-blind, randomized clinical trial of safety and effectiveness. J Bone Miner Res 2011;26:2341-57

[14]. RCOG scientific paper no.43 June 2014.

[15]. Hsu P, Santner-Nanan B, Dahlstrom JE, Fadia M, Chandra A, Peek M,et al. Altered decidual DC-SIGN+ antigen-presenting cells and impaired regulatory T-cell induction in preeclampsia. Am J Pathol 2012; 181: 2149 - 2160.

[16]. Erlebacher A. Mechanisms of T cell tolerance towards the allogeneic fetus. Nat Rev Immunol 2013; 13: 23-33.

[17]. Daftry GS,Taylor HS .Endocrine regulation of hox genes.Endo cr rev 2006;27:331-355.

[18]. Merke J, Hoffman W, Goldsmith D, Ritz E.Demonstration of 1, 25(OH)D receptors and actions in vascular smooth muscle cells in vitro.Calcif Tissue Int 1987;41:112-4.

[19]. Cardus A, Panizo S, Encinas M, Dolcet X, Gallego C, Aldea M, et al. 1,25-dihydroxyvitamin D3 regulates VEGF production through a vitamin D response element in the VEGF promoter. Atherosclerosis 2009; 204: 85-89.

[20]. Li YC, Kong J, Wei M, Chen ZF, Liu SQ, Cao LP. 1,25-Dihydroxyvitamin D(3) is a negative endocrine regulator of the reninangiotensin system. J Clin Invest 2002; 110: 229-238.

[21]. Kaur J, Marya RK, Rathee S, Lal H, Singh GP. Effect of pharmacological doses of vitamin D during pregnancy on placental protein status and birth weight. Nutrition Research 1991; 11(9):1077-1081.

[22]. Olsen SF, Secher NJ . A possible preventive effect of low-dose fish oil on early delivery and pre-eclampsia: indications from a 50year-old controlled trial. Br J Nutr 1990; 64:599-609 CrossRef, Medline.

[23]. Hollis BW, Wagner CL. Vitamin D and pregnancy: skeletal effects, nonskeletal effects, and birth outcomes. Calcif Tissue Int 2013; 92: $128-139$.

[24]. National High Blood Pressure Education Program Working Group on High Blood Pressure in Pregnancy. Report of the National High Blood Pressure Education Program Working Group on High Blood Pressure in Pregnancy. Am J Obstet Gynecol 2000; 183: $\mathrm{S} 1-\mathrm{S} 22$.

[25]. DeBoer IH, Ioannou GN, Kestenbaum B, Brunzell JD, Weiss NS. 25-Hydroxyvitamin D levels and albuminuria in the Third National Health and Nutrition Examination Survey (NHANES III). Am J Kid Dis 2007; 50(1): 69-77.

[26]. Reddy GS, Norman AW, Willis DM, et al. Regulation of vitamin D metabolism in normal human pregnancy. J Clin Endocrinol Metab. 1983; 56: 363-370.

[27]. Adorini L. Tolerogenic dendritic cells induced by vitamin D receptor ligands enhance regulatory $\mathrm{T}$ cells inhibiting autoimmune diabetes. Ann N Y Acad Sci. 2003; 987: 258-261. 